\title{
ANATOMIA E ONTOGÊNESE dA SÂMARA DE CENTROLOBIUM TOMENTOSUM Guill. ex Benth. (Leguminosae: Papilionoideae)
}

\author{
Denise Maria Trombert Oliveira ${ }^{1,4}$, Ana Cláudia Nóbrega Siqueira ${ }^{2}$ \& \\ Adriana Tiemi Nakamura ${ }^{3}$
}

\begin{abstract}
Resumo
(Anatomia e ontogênese da sâmara de Centrolobium tomentosum Guill. ex Benth. (Leguminosae: Papilionoideae)) Dalbergieae é considerada uma tribo basal de Papilionoideae (Leguminosae) e apresenta grande variação carpológica; apesar disso, poucos trabalhos analisam detalhadamente os órgãos reprodutivos destas plantas. O presente estudo teve como objetivo a descrição da anatomia e ontogênese da sâmara de Centrolobium tomentosum, verificando a origem da ala pericárpica e dos processos espiniformes presentes no núcleo seminífero. A ontogênese do pericarpo e da semente foi dividida em quatro estádios, ocorrendo o desenvolvimento concomitante do pericarpo e da semente, esta com características típicas de Papilionoideae. A ala pericárpica tem origem látero-estilar e os espinhos são formados por emergências ovarianas externas, de origem fundamental e epidérmica, sendo tardiamente vascularizadas. A dupla camada esclerenquimática (mesocarpo e endocarpo) presente no pericarpo maduro da sâmara de C. tomentosum pode ser considerada um estado plesiomórfico do caráter em relação a outras espécies de Dalbergieae descritas na literatura. Dos dados obtidos, destaca-se a presença de coléteres que é considerada uma sinapomorfia para os legumes dalbergióides (clado das Papilionoideae pantropicais).
\end{abstract}

Palavras-chave: Anatomia, Dalbergieae, ontogênese, pericarpo, sâmara, semente.

\section{Abstract}

(Anatomy and ontogeny of the fruit of Centrolobium tomentosum Guill. ex Benth. (Leguminosae: Papilionoideae)) Dalbergieae is considered a basal tribe of Papilionoideae (Leguminosae) and presents different types of fruits. The aim of this study was to describe the morphology, anatomy and ontogeny of the samaroid fruit of Centrolobium tomentosum, verifying the origin of the wing and external spines covering the seminal chamber. The pericarp and seed develop in parallel and the process was divided into four stages. The seed has typical Papilionoideae characters; the wing of the pericarp originates from the lateral portion of the style and the spines are produced by outer emergences of the ovary with dermal and mesophyll origin, and becoming vascularized late. The double layer of sclerenchyma (on the mesocarp and endocarp) present in the mature pericarp of the samaroid fruit of $C$. tomentosum can be considered a plesiomorphic state of character, when compared with other Dalbergieae species described in the literature. Our data show the presence of colleters, considered as a sinapomorphy for dalbergioid legumes (Papilionoideae pantropical clade).

Key words: Anatomy, Dalbergieae, ontogeny, pericarp, samara, seed.

\section{INTRODUÇão}

A subfamília Papilionoideae é a maior de Leguminosae, compreendendo aproximadamente 12.000 espécies distribuídas desde florestas tropicais até desertos secos e frios, apresentando representantes de importante papel na alimentação humana bem como na fertilização do solo (Prenner 2004).
A tribo Dalbergieae tem sido considerada um dos grupos ancestrais dentro da subfamília, tanto nas classificações tradicionais (Polhill et al. 1981) quanto nas filogenéticas (Pennington et al. 2001). Uma característica que se destaca no grupo é a grande variação carpológica, ocorrendo frutos drupáceos, frutos fibrosos e variadas formas de pericarpo

Artigo recebido em 03/2006. Aceito para publicação em 03/2007.

${ }^{1}$ UFMG - Universidade Federal de Minas Gerais, Instituto de Ciências Biológicas, Departamento de Botânica, Avenida Antonio Carlos, 6627, Pampulha, 31270-901, Belo Horizonte, MG, Brasil

${ }^{2}$ Departamento de Botânica, Instituto de Biociências, UNESP, Botucatu, SP, Brasil

${ }^{3}$ UNESP - Universidade Estadual Paulista, Instituto de Biociências, Programa de Pós-graduação em Ciências Biológicas, Biologia Vegetal, Rio Claro, SP, Brasil

${ }^{4}$ Autor para correspondência: dmtoliveira@icb.ufmg.br 
alado (Polhill et al. 1981), incluindo sâmaras típicas e frutos samaróides. Lima (1989-1990) citou somente frutos indeiscentes para a tribo, referindo sâmaras (incluindo neste termo aquelas de núcleo seminífero bem delimitado e os frutos samaróides) para 13 gêneros, além de núculas e drupas.

Nas espécies de Dalbergieae, variações quanto à formação da ala pericárpica foram registradas por Polhill (1981). As alas podem ter origem na expansão do pedúnculo (Platypodium Vogel) ou do estilete (Centrolobium Mart. ex Benth., Tipuana Benth.), na atenuação da margem do fruto ou fusão e achatamento das valvas (Pterocarpus L., Fissicalyx Benth.). Polhill (1981) enfatiza que os frutos das espécies dessa tribo são sempre indeiscentes, formando cavidades seminais em geral monospérmicas, delimitadas e protegidas pelo endocarpo lenhoso. A monospermia foi considerada constante nos frutos secos indeiscentes e nas drupas por Pijl (1982), embora Barroso et al. (1999) registrem que sâmaras e legumes samaróides formam de uma a poucas sementes.

Para o presente trabalho, selecionou-se Centrolobium tomentosum, espécie sobre a qual se encontram poucos estudos estruturais, restritos a qualificar aspectos da morfologia externa. Popularmente conhecida como araribá ou araribá-rosa, a espécie é amplamente utilizada como planta ornamental, na construção naval, marcenaria, agrossilvicultura e carpintaria em geral, além de apresentar um alto potencial como adubo verde (Diaz 1992), devido à sua simbiose com bactérias do gênero Rhizobium. No Brasil, é encontrada em encostas pedregosas da floresta semidecídua da bacia do Paraná, sendo encontrada também nos estágios iniciais da sucessão secundária e no interior de florestas primárias (Lorenzi 1992). O fruto característico da espécie tem núcleo seminífero basal lenhoso e equinado, sendo dividido por falsos septos; a ala é apical, sendo o estilete curvo e persistente. As sementes variam de uma a três (raramente quatro ou cinco), oblíquas ou transversais, com formato variando de oblonga a oblongoreniforme e apresentando testa papirácea e cotilédones crassos, plano-convexos (Barroso et al. 1984).

Os objetivos deste estudo são descrever a anatomia e ontogênese do pericarpo e semente de Centrolobium tomentosum, verificar a origem da ala pericárpica e esclarecer a natureza e constituição dos processos espiniformes do pericarpo, comparando os dados obtidos com outros referentes à tribo Dalbergieae.

\section{Material e Métodos}

Botões florais, flores em antese e pósantese e frutos em diversas fases de desenvolvimento de Centrolobium tomentosum foram fixados em FAA 50 (Johansen 1940) e conservados em álcool etílico $70 \%$. Ramos férteis foram herborizados e incluídos no acervo do herbário HRCB, do Departamento de Botânica, UNESP, Campus de Rio Claro, registrados sob o número 26.492.

Para a confecção do laminário permanente, após desidratação em série etílica, o material foi incluído em metacrilato e seccionado com cerca de $8 \mu \mathrm{m}$ de espessura. As secções obtidas foram coradas com azul de toluidina O (O'Brien et al. 1964) e montadas em Permount.

Foram também confeccionadas lâminas semipermanentes de material cujos tricomas foram parcialmente removidos com fita adesiva. As secções foram coradas com azul de astra e safranina (Bukatsch 1972; Burger \& Richter 1991) e montadas em gelatina glicerinada.

Realizaram-se testes histoquímicos, utilizando os seguintes corantes e reagentes: vermelho de rutênio (Jensen 1962), floroglucinol em meio ácido (Sass 1951), Sudan IV, lugol e cloreto férrico (Johansen 1940).

Para a descrição do desenvolvimento do pericarpo, adotou-se o conceito ontogenético, considerando o exocarpo derivado da epiderme externa do ovário, o mesocarpo do mesofilo ovariano e o endocarpo da epiderme interna 
(sensu Roth 1977). A terminologia para descrição da semente segue Corner (1976) e Oliveira (1999). A divisão em estádios de desenvolvimento dos frutos e sementes foi feita conforme o proposto por Lilleland (1930; 1932; 1933), Tukey \& Young (1939) e Nitsch (1953).

O laminário preparado foi analisado em microscópio óptico e ilustrado por meio de fotomicrografias obtidas em fotomicroscópio Zeiss. Para todas as ilustrações, foram preparadas escalas nas condições ópticas adequadas.

\section{Resultados}

Em Centrolobium tomentosum, observase desenvolvimento simultâneo do pericarpo e da semente que pode ser descrito em quatro estádios: estádio I - ovário e óvulo sem atividade meristemática; estádio II - divisões celulares no pericarpo e semente; estádio III alongamento celular no pericarpo e semente; estádio IV - maturação do pericarpo e semente, destacando-se a lignificação pericárpica.

Estádio I (Figs. 1-4)

O ovário é unilocular e apresenta aspecto ovalado em secção transversal (Fig. 1), com epiderme externa unisseriada, composta por células cubóides (Fig. 2) e tricomas pluricelulares (Fig. 3), tectores e secretores, ainda pouco diferenciados.

O mesofilo ovariano é composto por parênquima fundamental, ocorrendo idioblastos fenólicos, acompanhando o contorno da epiderme externa, assim como associados aos feixes vasculares (Figs. 1, 3). Imersos no mesofilo, são observados dois feixes ventrais e um dorsal (Fig. 1); ocorrem, ainda, cordões procambiais laterais (Fig. 2). Idioblastos cristalíferos são localizados preferencialmente nas proximidades dos feixes vasculares.

A epiderme interna é unisseriada, e suas células apresentam também aspecto cubóide, porém com maiores dimensões que as da epiderme externa (Figs. 1-2, 4).

$\mathrm{O}$ ovário geralmente contém de dois a três óvulos, dispostos em uma única fileira, com placentação parietal. Os óvulos são campilótropos e bitegumentados (Fig. 4). O tegumento externo é mais espesso, exibindo de três a cinco camadas celulares; na maior extensão do tegumento interno, observam-se apenas duas camadas de células (Fig. 4).

Ainda nesta fase, inicia-se a formação de algumas emergências (Fig. 1), que se projetam a partir do mesofilo carpelar parenquimático, sendo revestidas pela epiderme externa do ovário.

\section{Estádio II (Figs. 5-16)}

No ovário da flor em pré-antese, iniciase a formação de um primórdio de ala que é látero-estilar, o qual se amplia durante a antese e pós-antese (Fig. 5). Tanto o estilete quanto a ala são ricamente vascularizados (Fig. 5) e apresentam numerosos idioblastos fenólicos. Sua constituição é semelhante à do ovário, sendo o lóculo reduzido ao canal estilar.

As emergências que se projetam para o exterior do carpelo tornam-se mais nítidas e freqüentes, sendo observadas inicialmente na região proximal do ovário (Figs. 5-7). Também são produzidas emergências que se projetam para o interior do lóculo carpelar, compartimentalizando o fruto quando completamente desenvolvidas (Figs. 5-6).

Tanto o pericarpo jovem quanto o estilete e o primórdio de ala apresentam estômatos dispersos em diferenciação; contudo, sua visualização é comprometida, visto que se encontram recobertos por densa pilosidade (Fig. 5). São observados tricomas secretores (Fig. 9) e tectores (Figs. 10-13), ambos multicelulares.

Os tricomas secretores são multisseriados, pedunculados e capitados (Fig. 8-9). Suas células apresentam, em geral, paredes delgadas, tanto no pedúnculo quanto na porção apical (Fig. 9). O pedúnculo é caracterizado por células com grandes vacúolos, e as células da porção apical por apresentarem citoplasma denso (Fig. 9), com núcleos volumosos e acúmulo de substâncias lipídicas e fenólicas. Dadas as suas características, tais estruturas são denominadas coléteres. 

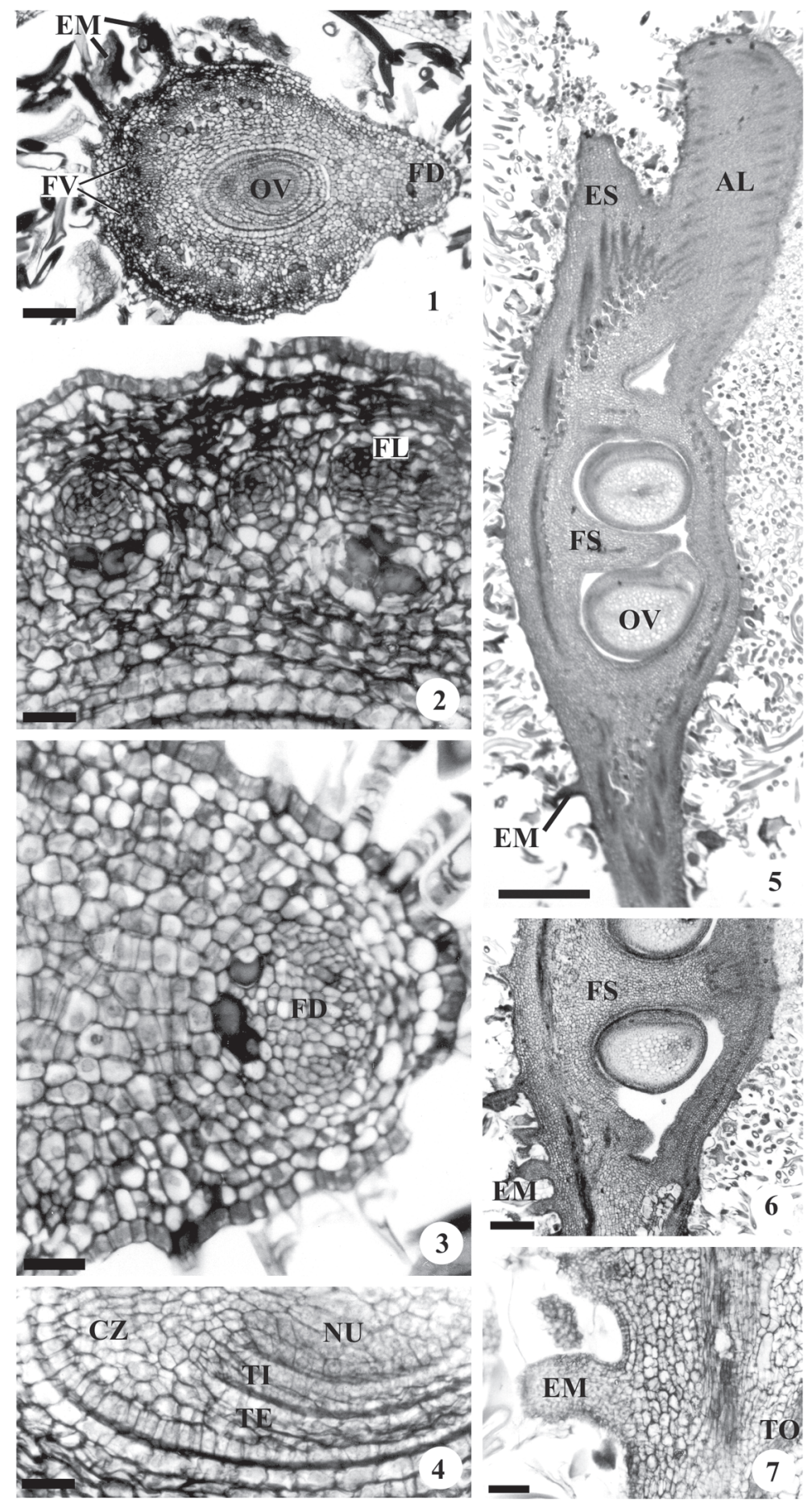

Figuras 1-7 - Centrolobium tomentosum. Secções transversais (1-4). Secções longitudinais (5-7). 1-4. Botão floral (Estádio I). 1. Aspecto geral do ovário. 2. Detalhe da lateral do ovário, mostrando os cordões procambiais laterais. 3. Feixe dorsal do ovário. 4. Detalhe do óvulo, mostrando os tegumentos e o aspecto do nucelo e da calaza. 5-7. Flor em antese (Estádio II). 5. Vista geral, destacando a estipe na base do ovário, onde se inicia a formação de emergências externas; notar, no ápice, o estilete e primórdio de ala. 6. Detalhe do ovário, mostrando óvulos e falso septo. 7. Detalhe da parede ovariana, exibindo emergência externa. $(\mathrm{AL}=$ ala; $\mathrm{CZ}=$ calaza; $\mathrm{EM}=$ emergência externa; $\mathrm{ES}=$ estilete; $\mathrm{FD}=$ feixe dorsal; $\mathrm{FL}=$ precursor do feixe lateral; $\mathrm{FS}=$ falso septo; $\mathrm{FV}=$ feixe ventral; $\mathrm{NU}=$ nucelo; $\mathrm{OV}=$ óvulo; $\mathrm{TE}=$ tegumento externo; $\mathrm{TI}=$ tegumento interno; $\mathrm{TO}=$ traço vascular do óvulo). Barras = $1 \mu \mathrm{m}(5) ; 200 \mu \mathrm{m}(6) ; 100 \mu \mathrm{m}(1) ; 25 \mu \mathrm{m}(2-4,7)$. 


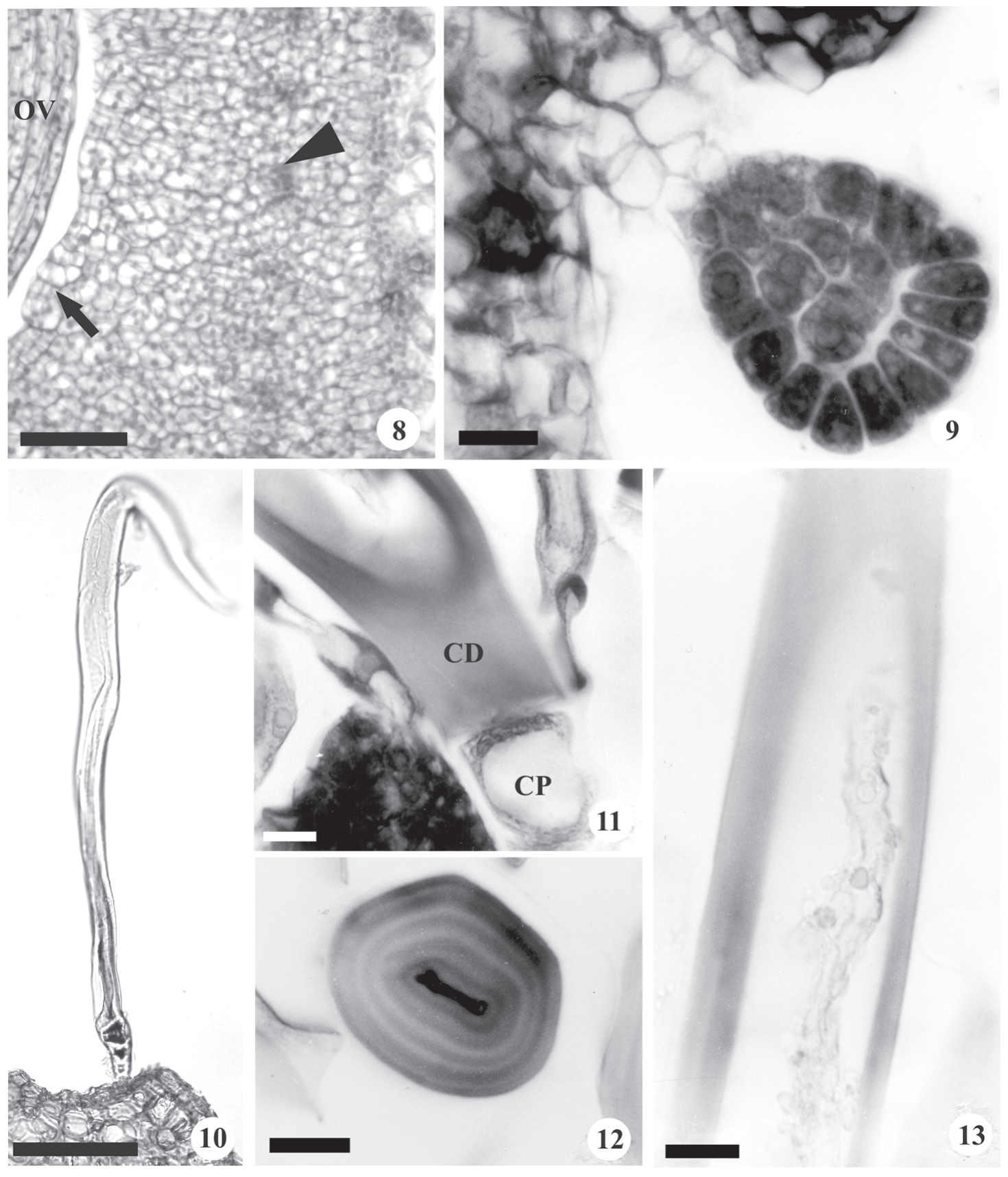

Figuras 8-13 - Centrolobium tomentosum. Flor em antese (Estádio II). Secções longitudinais (8-9, 11, 13). Secção transversal (12). 8. Vista geral do ovário, destacando cordões procambiais individualizados (ponta de seta) e divisões periclinais na epiderme interna (seta). 9. Detalhe do coléter. 10. Aspecto do tricoma tector pluricelular. 11. Detalhe da base do tricoma tector, destacando a diferença de espessura de uma célula proximal e da distal. 12. Detalhe do espessamento lamelado basal da célula distal do tricoma tector. 13. Detalhe da célula distal, mostrando a espessura da parede e o conteúdo celular. $(\mathrm{CD}=$ célula distal; $\mathrm{CP}=$ célula proximal; $\mathrm{OV}=$ óvulo). Barras = $100 \mu \mathrm{m}(10) ; 50 \mu \mathrm{m}(8) ; 10 \mu \mathrm{m}(9,11-13)$. 
Os tricomas tectores ocorrem em maior densidade que os secretores e apresentam-se multicelulares e unisseriados (Figs. 10-11). A porção proximal é constituída por duas ou mais células de paredes pecto-celulósicas bastante delgadas, citoplasma ativo e mostram-se amplamente vacuoladas (Fig. 11). Distalmente, observa-se uma única célula alongada, que apresenta grande espessamento parietal (Figs. 12-13) especialmente em sua base; nessa região, verifica-se nítida lamelação parietal (Fig. 12), porém mantendo conteúdo ativo na porção mediana (Fig. 13).

No mesocarpo, ocorre intensa proliferação celular. As divisões não são regularmente distribuídas, sendo mais freqüentes nas regiões que produzem as emergências para o exterior e interior do fruto. No restante do mesocarpo, amplia-se o número de camadas celulares e os cordões procambiais que constituirão os feixes laterais tornam-se mais numerosos e afastados uns dos outros (Fig. 8). Grande número de idioblastos fenólicos de arranjo irregular é produzido nesta fase, observando-se também, principalmente junto da estipe, tendência à formação de canais secretores, resultantes da fusão de idioblastos.

Próximo à base das emergências externas, verifica-se a existência de intensa rede de feixes vasculares pouco diferenciados, os quais são responsáveis também pela irrigação dos óvulos na face ventral (Fig. 7).

As emergências internas em formação atravessam a cavidade seminal, produzindo falsos septos, por vezes isolando várias cavidades no fruto jovem (Figs. 5-6). Observou-se que estas emergências internas não são vascularizadas e não se localizam próximas aos feixes vasculares. Estas são constituídas por células derivadas de intensas divisões de células fundamentais do mesofilo e da epiderme interna do ovário. Deve ser destacado que as emergências internas assumem posições variáveis, sendo por vezes transversais e, na maioria dos casos, oblíquas. Desta maneira, são produzidas várias cavidades seminais, algumas delas não envolvendo sementes em desenvolvimento. Como muitas das emergências internas são oblíquas, verifica-se, quando em secção transversal, a ocorrência de mais de uma cavidade seminal num mesmo nível do pericarpo jovem.

$O$ endocarpo também se torna multiplicativo, dividindo-se periclinalmente (Fig. 8). As divisões prosseguem, definindo duas regiões com células distintas: o endocarpo externo e o interno.
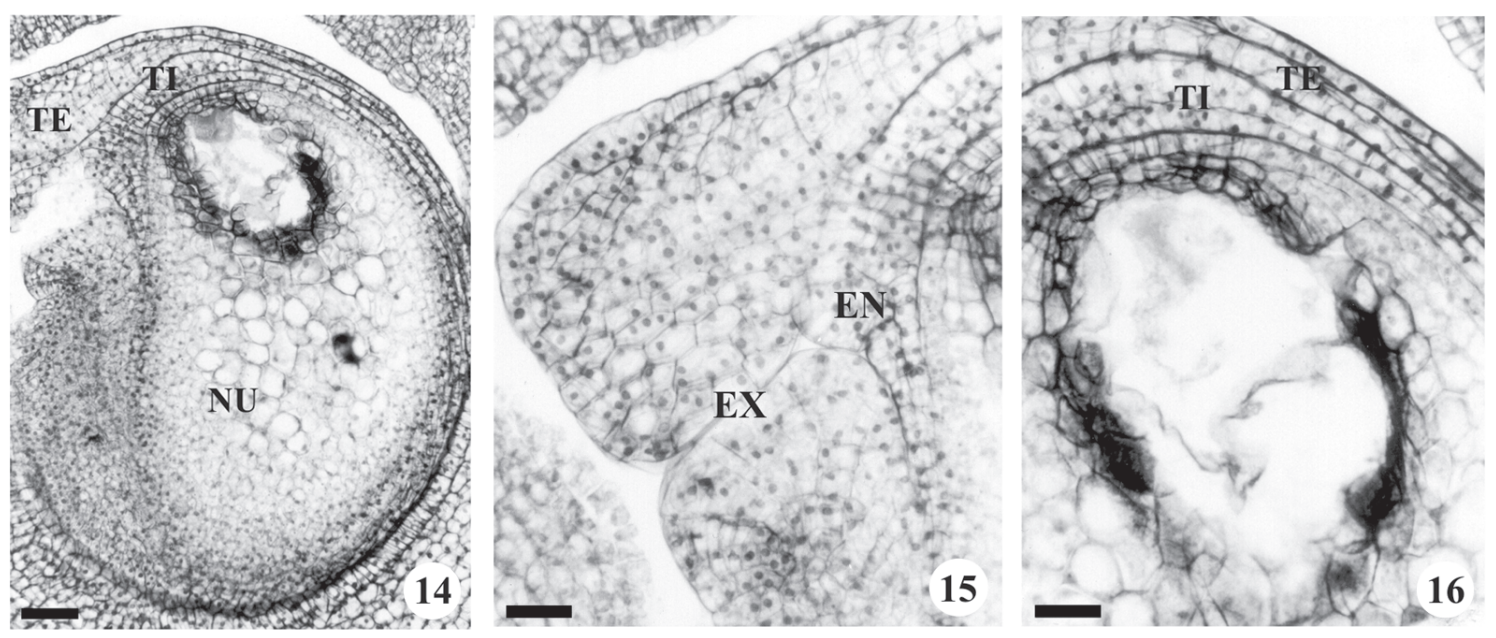

Figuras 14-16 - Centrolobium tomentosum. Semente jovem (Estádio II). Secções longitudinais. 14. Vista geral. 15. Detalhe da micrópila, mostrando exóstoma e endóstoma. 16. Detalhe da Figura 14, mostrando os tegumentos, o nucelo em processo de reabsorção e o início de formação de endosperma. $(\mathrm{EN}=$ endóstoma; $\mathrm{EX}=$ exóstoma; $\mathrm{NU}=$ nucelo; $\mathrm{TE}=$ tegumento externo; $\mathrm{TI}=$ tegumento interno). Barras $=50 \mu \mathrm{m}(14) ; 25 \mu \mathrm{m}(15-16)$. 
Durante o estádio II, a semente jovem mantém estrutura muito similar à do óvulo (Fig. 14). A micrópila apresenta ligeiro zigue-zague, com exóstoma bem amplo e endóstoma reduzido (Figs. 14-15). O nucelo é composto por células bem vacuoladas e parcialmente digeridas (Figs. 14, 16). Internamente, observase o início de formação do endosperma, que é nuclear (Fig. 16).

\section{Estádio III (Figs. 17-29)}

Neste estádio, que abrange o alongamento do fruto até seu tamanho final, observam-se poucas variações no exocarpo, verificando-se poucos estômatos, numerosos tricomas tectores (Figs. 17-19, 22-23) e coléteres em senescência (Figs. 18, 23).

Durante o estádio III, há irrigação das emergências externas pela rede vascular presente em sua base que, neste momento, apresenta feixes diferenciados. As emergências externas passam a constituir verdadeiros espinhos (Fig. 18).

O mesocarpo apresenta a diferenciação de blocos de fibras (Figs. 17-18, 20), alongados em diversas direções (Figs. 20-21), entremeados por células parenquimáticas (Figs. $18,20)$, entre as quais se encontram numerosos idioblastos cristalíferos contendo cristais prismáticos de oxalato de cálcio (Fig. 21) e idioblastos fenólicos (Figs. 17-20). Estes idioblastos podem se fundir a outros, constituindo canais secretores (Fig. 19). Próximo das camadas subepidérmicas, as fibras constituem uma camada quase ininterrupta (Fig. 18), acrescida dos feixes vasculares que irrigam o pericarpo.

Devido à formação das emergências internas, ocorrida no estádio anterior, pode-se localizar mais de uma cavidade seminal quando se analisam secções transversais (Fig. 17). Ao redor de cada cavidade seminal, o endocarpo externo diferencia-se em fibras e o interno em parênquima (Figs. 17, 22). Algumas dessas cavidades aparecem quase totalmente colapsadas, não envolvendo semente em desenvolvimento.
A ala exibe estrutura similar ao núcleo seminífero no exocarpo e no mesocarpo, sem, contudo, apresentar blocos de fibras (Figs. 22-23). Apenas a região interna do endocarpo se desenvolve, estando representado somente por células parenquimáticas, formadas como continuação do endocarpo interno (Fig. 22). Estas células ficam pouco distintas, comprimidas entre os feixes vasculares laterais (Fig. 23). Na extremidade da ala, observa-se o feixe vascular dorsal, acompanhado por diversos idioblastos fenólicos (Fig. 23).

A semente em estádio pré-maturação apresenta-se alongada longitudinalmente (Fig. 24), variando de elíptica a ovada no plano transversal (Figs. 26-28). Sobre o lobo radicular, observa-se a micrópila (Fig. 24), o hilo (Figs. 24, 28), a rafe (Figs. 24, 27) e a calaza (Fig. 26). A anti-rafe não é vascularizada (Figs. 24-26). Na região subhilar, inicia-se a diferenciação da barra de traqueídes e o acúmulo de substâncias fenólicas (Figs. 28-29).

A semente é revestida pela testa e resquícios celulares do tégmen, que se encontra em compressão (Fig. 25). A epiderme externa da testa apresenta células alongadas, em paliçada (Fig. 25), contendo compostos fenólicos. O mesofilo é parenquimático e inclui o feixe rafeal (Fig. 27) que, na calaza, apresenta arranjo frouxo (Fig. 26). A epiderme interna é distinta, mantendo-se justaposta aos resquícios celulares do tégmen (Fig. 25). Resíduos nucelares ainda podem ser observados nas adjacências da calaza (Figs. 24, 26).

O endosperma encontra-se celularizado nas camadas periféricas, especialmente ao redor do embrião (Fig. 25); no centro, mantém-se nuclear (Figs. 24, 26-28).

$\mathrm{O}$ embrião encontra-se em fase inicial de maturação. Verifica-se a presença do suspensor, composto por células vacuoladas, e do embrião globular, que apresenta células de grande densidade citoplasmática (Fig. 25). 


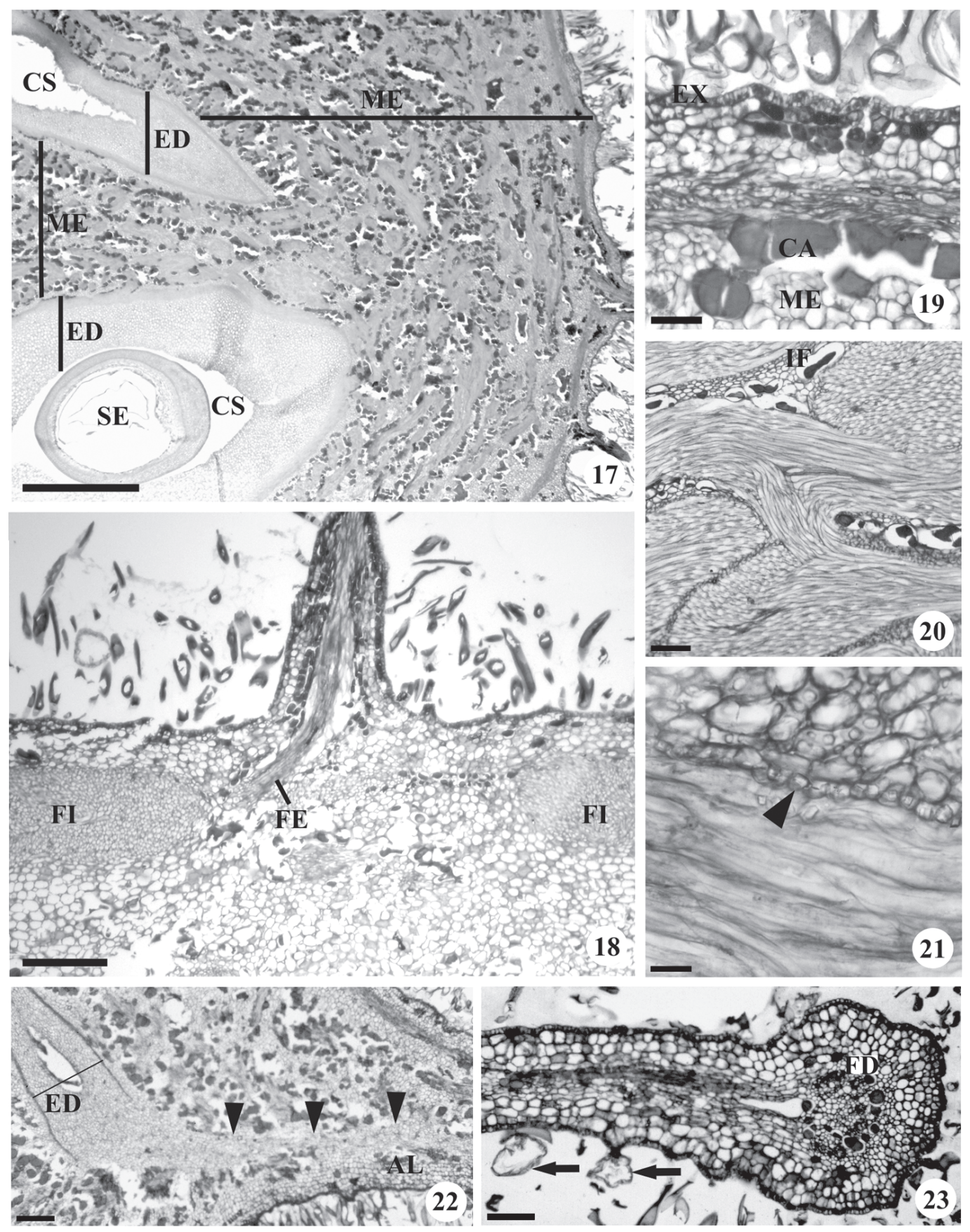

Figuras 17-23 - Centrolobium tomentosum. Pericarpo (Estádio III). Secções transversais. 17. Aspecto geral, mostrando o mesocarpo compartimentalizado e duas regiões de endocarpo, delimitando cavidades seminais. 18. Aspecto geral do exocarpo e mesocarpo, destacando as fibras mais externas do mesocarpo; notar a ramificação vascular para o espinho. 19. Detalhe do canal secretor em formação no mesocarpo. 20. Detalhe das fibras do mesocarpo, próximas a idioblastos fenólicos. 21. Detalhe do mesocarpo com cristais prismáticos de oxalato de cálcio (ponta de seta), em células margeando blocos de fibras. 22. Região de transição do núcleo seminífero para a ala, mostrando continuidade do parênquima do endocarpo interno até a região da ala (pontas de seta). 23. Aspecto geral da extremidade dorsal da ala. $(\mathrm{AL}=\mathrm{ala} ; \mathrm{CA}=$ canal secretor; $\mathrm{CS}=$ cavidade seminal $; \mathrm{ED}=$ endocarpo; $\mathrm{EX}=$ exocarpo; $\mathrm{FD}=$ feixe dorsal $; \mathrm{FE}=$ feixe vascular; $\mathrm{FI}=$ fibra; $\mathrm{IF}=$ idioblasto fenólico; $\mathrm{ME}=$ mesocarpo; $\mathrm{SE}=$ semente; seta = coléter em senescência). Barras = $1 \mu \mathrm{m}(17-18) ; 200 \mu \mathrm{m}$ (22); $100 \mu \mathrm{m}(20,23) ; 50 \mu \mathrm{m}$ (19); $25 \mu \mathrm{m}$ (21). 


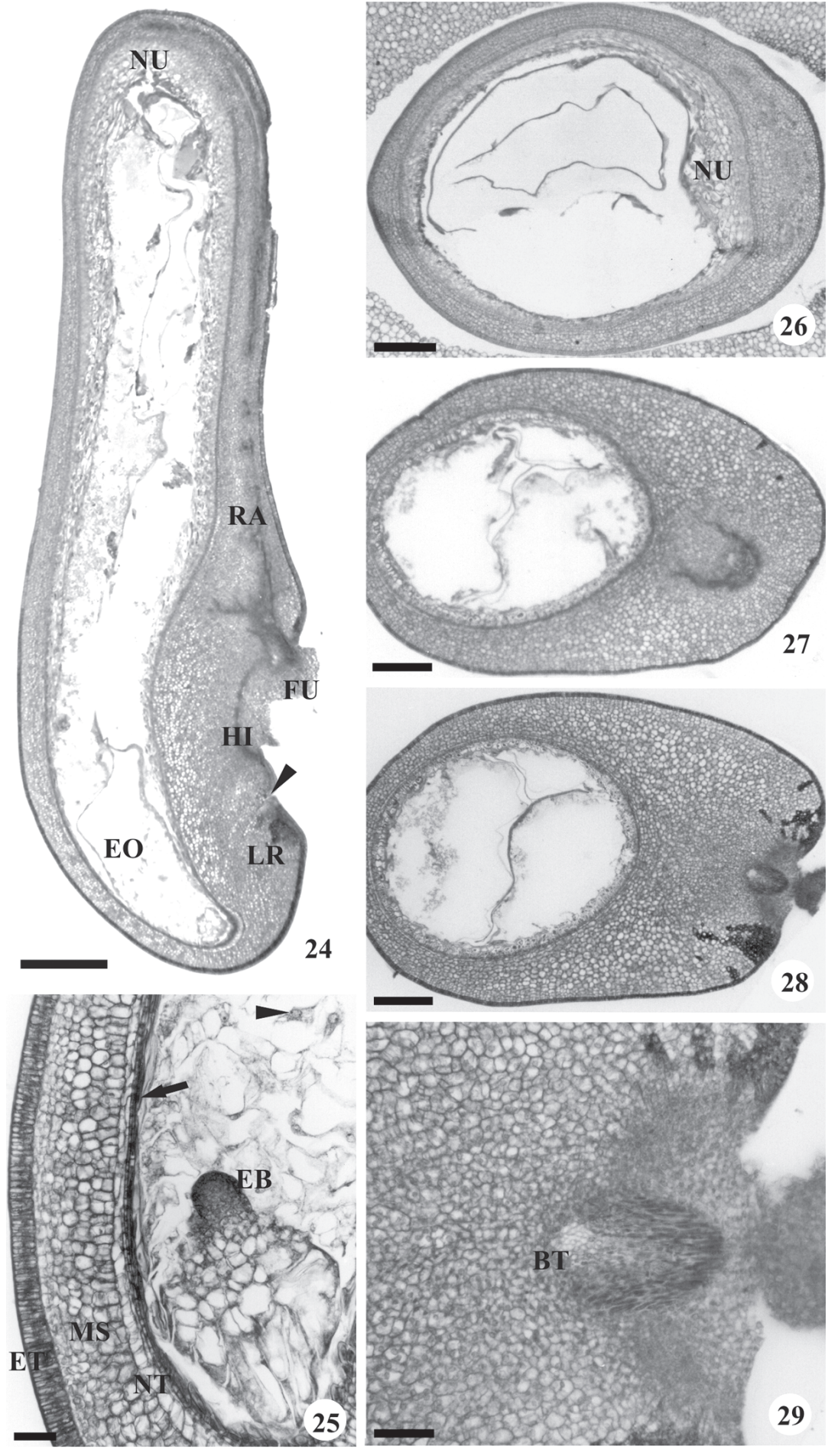

Figuras 24-29 - Centrolobium tomentosum. Semente (Estádio III). Secções longitudinais (24-25). Secções transversais (26-29). 24. Vista geral da semente (ponta de seta: micrópila). 25. Detalhe da testa, tégmen comprimido (seta), endosperma em formação com núcleos livres (ponta de seta) e o embrião. 26. Região calazal. 27. Região rafeal. 28. Região hilar. 29. Detalhe da região hilar, mostrando a barra de traqueídes em diferenciação. (BT = barra de traqueídes; EB = embrião; EO = endosperma : $\mathrm{ET}=$ epiderme externa da testa $; \mathrm{FU}=$ funículo HI = hilo; $\mathrm{LR}=$ lobo radicular; $\mathrm{MS}=$ mesofilo; $\mathrm{NT}=$ epiderme interna da testa; $\mathrm{NU}=$ nucelo; $\mathrm{RA}=$ rafe). Barras $=2 \mu \mathrm{m}(24) ; 200 \mu \mathrm{m}(26-28) ; 50 \mu \mathrm{m}(25,29)$. 
Estádio IV (Figs. 30-43)

O fruto é uma sâmara estipitada de coloração marrom-escura, cujo núcleo seminífero é arredondado e proximal, apresentando finos e longos espinhos. Sua ala é distal, ampla e bem vascularizada. Cada semente ocupa uma cavidade seminal própria (Fig. 30), isolada por tecidos de grande rigidez.

Os espinhos do núcleo seminífero (Figs. 30-32) apresentam a estrutura exocárpica similar ao restante do fruto, destacando-se a presença dos tricomas tectores e secretores, além de estômatos em elevação (Figs. 31-32). As células comuns da epiderme variam de cubóides a ligeiramente alongadas no sentido radial. No sistema fundamental, observam-se de duas a três camadas parenquimáticas, com idioblastos fenólicos dispersos (Figs. 31-32), seguidas por um anel multisseriado e quase contínuo de fibras bem diferenciadas; internamente, de uma a três camadas fenólicas envolvem novo anel de fibras com número variável de camadas, rodeando pequenos feixes vasculares (Fig. 31).

O exocarpo, tanto no núcleo seminífero maduro quanto na ala, possui células cubóides, alguns estômatos (Fig. 33), além de tricomas tectores pluricelulares e unisseriados, com células proximais de paredes suberificadas e distal de natureza péctica. Poucos coléteres ainda exibem o conteúdo, a maioria encontrando-se rompidos ao final do desenvolvimento do fruto.

$\mathrm{Na}$ extremidade dorsal da ala, o revestimento epidérmico é substituído por súber (Figs. 36-38), o qual é produzido por divisões periclinais na camada subepidérmica (Fig. 37); ocasionalmente, são observadas lenticelas. Alguns trechos das laterais da ala também aparecem revestidos pelo súber na maturidade (Fig. 30), enquanto que, em outros, a epiderme é mantida (Figs. 33, 36).

No mesocarpo do núcleo seminífero (Fig. 30), prevalecem os blocos de fibras, agora lignificados, dispostos em várias direções e entremeados com células parenquimáticas entre as quais ocorrem canais secretores de conteúdo misto, de natureza lipídica e fenólica. Cristais prismáticos de oxalato de cálcio acompanham os blocos de fibras.

$\mathrm{Na}$ ala, o mesocarpo apresenta algumas camadas de parênquima, após as quais observam-se feixes vasculares (Figs. 33-34). O feixe dorsal, assim como os ventrais, é acompanhado por fibras que apresentam leve lignificação e evidente acúmulo de substâncias pécticas em suas paredes. Associados aos feixes de maior calibre, principalmente ao dorsal e ventrais, são encontrados numerosos e conspícuos canais secretores (Figs. 36, 3840), similares aos descritos no núcleo seminífero.

No endocarpo do núcleo seminífero, distinguem-se duas regiões (Fig. 30), já definidas no estádio anterior: uma camada maciça de fibras dispostas obliquamente (endocarpo externo) e outra de parênquima, onde se encontram esporadicamente alguns cristais prismáticos de oxalato de cálcio (endocarpo interno).

$\mathrm{Na}$ ala, o endocarpo é composto por aerênquima (Figs. 33-35), tecido de origem idêntica à do endocarpo interno parenquimático do núcleo seminífero (Fig. 30). De modo similar ao núcleo seminífero, são observados idioblastos e canais secretores (Figs. 33-34, 36, 38-40), de secreção fenólica e lipídica. Diminutos grãos de amido ocorrem na ala, sendo mais concentrados nas regiões circunvizinhas aos feixes vasculares.

O estrato esclerenquimático do pericarpo de C. tomentosum é, portanto, constituído tanto pelos blocos de fibras mesocárpicos quanto pelo endocarpo externo fibroso.

A semente é alongada e achatada, de coloração castanho-clara, com proeminente lobo radicular sobre o qual se identifica a micrópila. O hilo é conspícuo e se encontra próximo à micrópila. Dele parte a rafe, visível externamente como um traço marrom, mais escuro que o restante do tegumento.

Verifica-se que a semente é presa ao pericarpo pelo funículo parenquimatoso, irrigado por um único feixe vascular. 

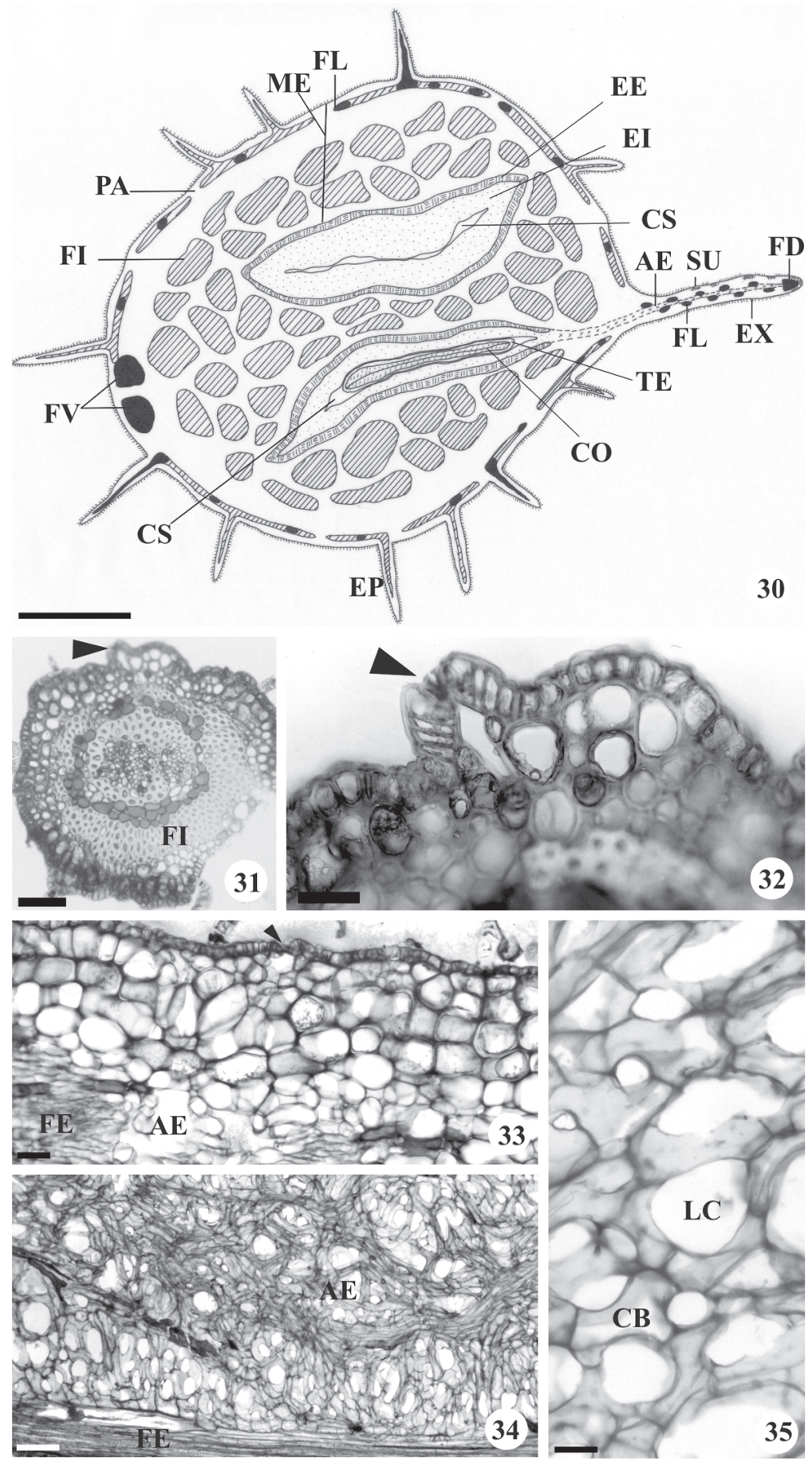

Figuras 30-35 - Centrolobium tomentosum. Fruto maduro (Estádio IV). Secções transversais (30-33). Secções longitudinais (34-35). 30. Diagrama do núcleo seminífero do fruto maduro, passando pela base da ala. 31. Aspecto geral do espinho, destacando estômato (ponta de seta). 32. Detalhe do espinho, exibindo o estômato (ponta de seta). 33. Detalhe da ala; notar o parênquima aerífero e estômato (ponta de seta). 34. Vista da ala, evidenciando o aerênquima próximo a um feixe vascular. 35. Detalhe do parênquima aerífero. $(\mathrm{AE}=$ aerênquima; $\mathrm{CB}=$ célula braciforme; $\mathrm{CS}=$ cavidade seminal; $\mathrm{CO}=$ cotilédone; $\mathrm{EE}=$ endocarpo externo $; \mathrm{EI}=$ endocarpo interno; $\mathrm{EP}=$ espinho; $\mathrm{EX}=$ exocarpo; $\mathrm{FD}=$ feixe dorsal; $\mathrm{FE}=$ feixe vascular; $\mathrm{FI}=$ fibra; $\mathrm{FL}=$ feixe lateral $; \mathrm{FV}=$ feixe ventral $; \mathrm{LC}=$ lacuna $; \mathrm{ME}=$ mesocarpo $; \mathrm{PA}=$ parênquima; $\mathrm{SU}=$ súber; $\mathrm{TE}=$ testa $)$. Barras $=500 \mu \mathrm{m}(30) ; 100 \mu \mathrm{m}(31,34) ; 50 \mu \mathrm{m}(33) ; 25 \mu \mathrm{m}(34,35)$. 

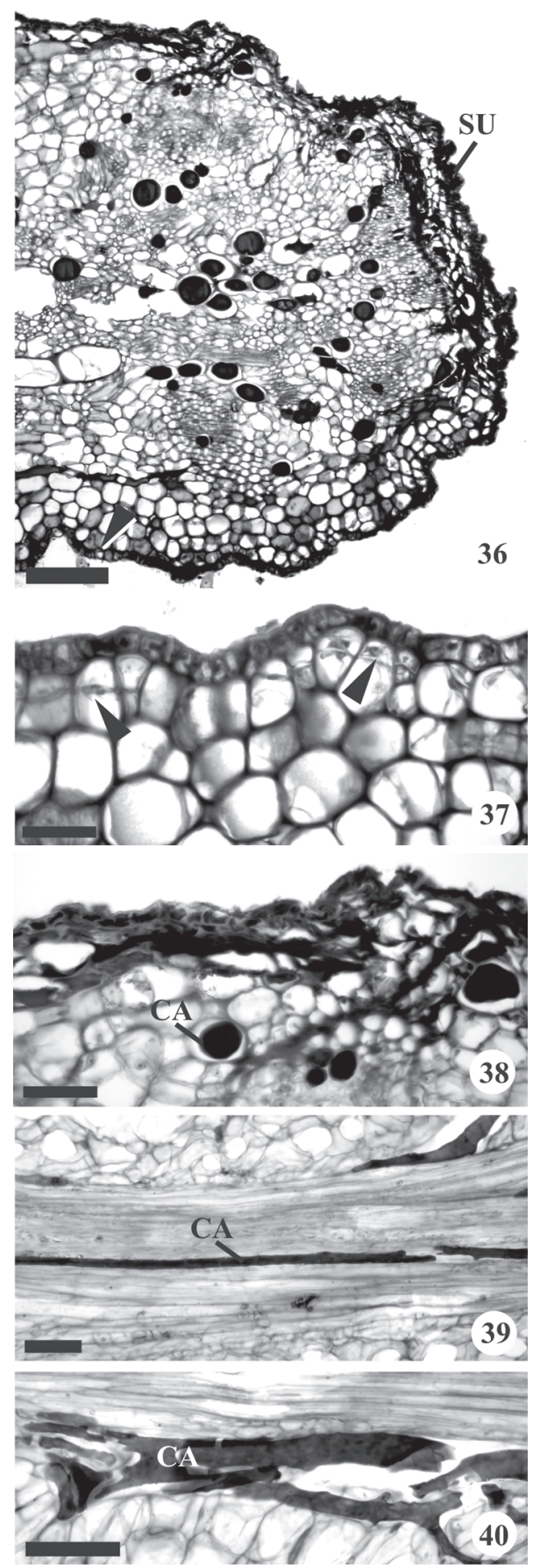

Figuras 36-40 - Centrolobium tomentosum. Ala do fruto maduro (Estádio IV). Secções transversais (36-38). Secções longitudinais (39-40). 36. Aspecto do feixe dorsal, destacando um trecho de súber; notar também trechos de epiderme (ponta de seta). 37. Detalhe do início de produção do súber (ponta de seta: divisão periclinal). 38 . Detalhe do súber. 39. Detalhe do feixe dorsal, com canal secretor. 40. Detalhe de canal secretor entre um feixe lateral e o aerênquima. ( $\mathrm{CA}=$ canal secretor; $\mathrm{SU}=$ súber). Barras $=150 \mu \mathrm{m}(36,39) ; 100 \mu \mathrm{m}(38,40) ; 50 \mu \mathrm{m}(37)$.
A testa apresenta uma camada paliçádica, que constitui sua epiderme externa (Fig. 41), rica em compostos fenólicos. Na mesotesta, encontram-se células parenquimáticas. A vascularização seminal está representada apenas por um feixe vascular de pequeno calibre, que parte da região hilar, percorre a rafe e atinge a calaza pouco distinta. A epiderme interna da testa é unisseriada, composta por células alongadas radialmente (Fig. 41).
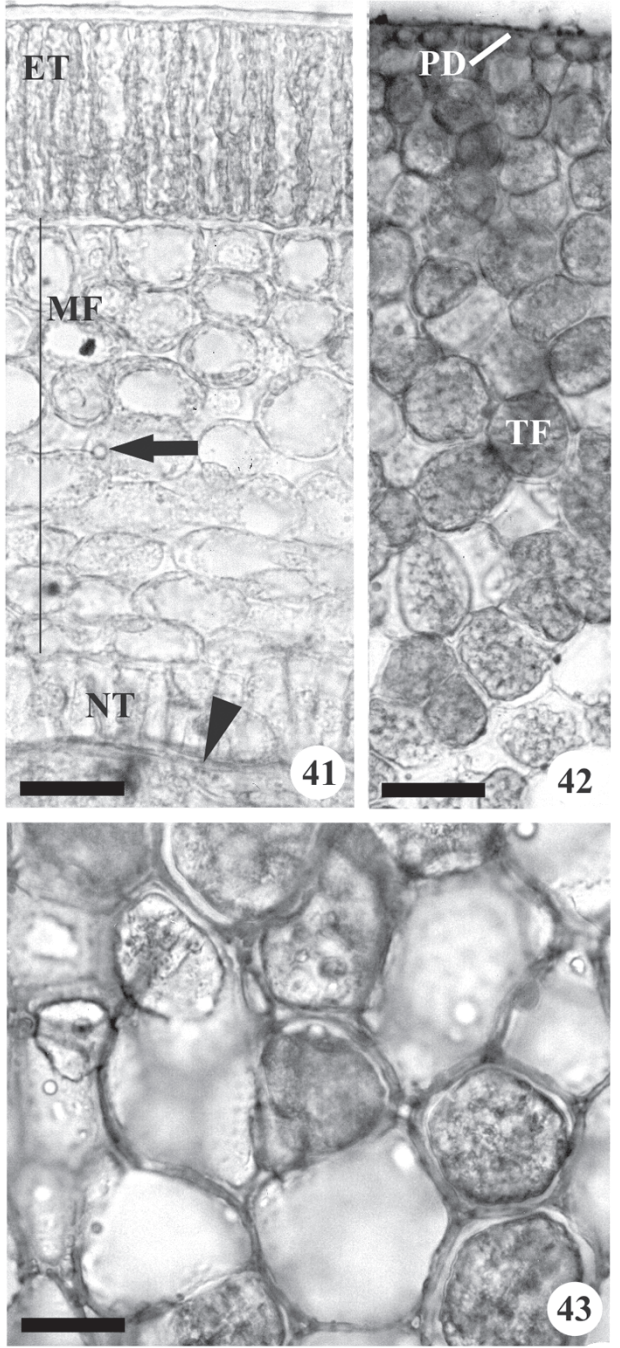

Figuras 41-43 - Centrolobium tomentosum. Semente madura (Estádio IV). Secções transversais. 41. Aspecto geral da testa (seta: gotícula lipídica; ponta de seta: resíduos de tégmen e endosperma). 42. Cotilédone. 43. Detalhe das células do tecido fundamental cotiledonar. $(\mathrm{ET}=$ epiderme externa da testa; $\mathrm{MF}=$ mesotesta; $\mathrm{NT}=$ epiderme interna da testa $\mathrm{PD}=$ protoderme $\mathrm{TF}=$ tecido fundamental). Barras $=50 \mu \mathrm{m}(42) ; 25 \mu \mathrm{m}(41,43)$. 
O hilo possui dupla camada paliçádica, revestindo amplo tecido sub-hilar parenquimático. Nesta região, ocupando a porção mediana, observa-se a presença da barra de traqueídes. Rodeando o hilo subepidermicamente, há grande acúmulo de células ricas em compostos fenólicos, que conferem coloração mais escura a esta região. Toda a região sub-hilar apresenta acúmulo de pequenos grãos de amido.

Internamente à testa, ocorrem apenas resíduos das células tégmicas e endospérmicas (Fig. 41), visto que a semente é exalbuminosa na maturidade.

O embrião é constituído por dois cotilédones plano-convexos e assimétricos, unidos ao eixo embrionário bem diferenciado. Os cotilédones são carnosos, revestidos por protoderme de células cubóides (Fig. 42). O tecido fundamental tem células isodiamétricas de tamanhos variáveis, de paredes pécticas levemente espessadas, que delimitam pequenos meatos (Fig. 43). São células preenchidas por substâncias de reserva, verificando-se conteúdo lipídico e, provavelmente, protéico.

\section{Discussão}

De modo geral, a estrutura do ovário e óvulo de Centrolobium tomentosum é similar à observada para outras espécies de leguminosas (Oliveira \& Beltrati 1993; Martins \& Oliveira 2001; Colpas \& Oliveira 2002; Pietrobom \& Oliveira 2004; Nakamura \& Oliveira 2005; Oliveira \& Paiva 2005).

Dos dados obtidos, destaca-se o arranjo e composição da superfície ovariana e pericárpica, especialmente os tipos de tricomas e a ocorrência de emergências. Já era esperado encontrar indumento denso em $C$. tomentosum, visto que esta característica foi registrada diretamente em seu epíteto específico.

Segundo Theobald et al. (1979), altas densidades de tricomas estão relacionadas à defesa da planta, especialmente contra insetos fitófagos. Os referidos autores afirmam que os tricomas podem complementar a defesa química do vegetal, produzida pela formação e exudação de terpenos, fenóis, alcalóides e outras substâncias, que agem como repelentes pelo sabor e/ou odor desagradável. No ovário e fruto de $C$. tomentosum, a alta frequiência de idioblastos fenólicos pode ter o significado referido por Theobald et al. (1979).

Tricomas secretores de cabeça multicelular são denominados coléteres por Radford et al. (1974), que afirmam que esses tricomas podem ser pedunculados ou não. Segundo Thomas (1991), coléteres são os tricomas glandulares encontrados nas gemas apicais caulinares, secretando substâncias mucilaginosas ou resinosas, que protegem o meristema apical. Embora o termo coléter seja o mais empregado para estas estruturas, alguns autores denominam-nas apenas glândulas ou tricomas glandulares, glândula péctica, glândula resinosa, entre outros.

De acordo com Fahn (1979), os coléteres iniciam sua atividade muito precocemente, fato observado neste trabalho. Depois de cessar sua atividade secretora, o coléter senesce, tornando-se amarronzado e passando, por fim, à necrose. A necrose inicia-se no ápice do coléter, adelgaçando-se as paredes celulares e degenerando o citoplasma, basipetamente, pelo coléter (Thomas 1991). A sequiência de fenômenos descrita enquadra-se perfeitamente no observado neste trabalho.

A maior parte dos relatos de ocorrência de coléteres está ligada aos limbos, pecíolos e estípulas, mas há registros de coléteres em brácteas, cálices e corolas (Thomas 1991), podendo também ser encontrados em ovários e frutos (Lavin et al. 2001). Lavin et al. (2001) denominam o coléter como glândula pustular e afirmam que esta glândula é uma sinapomorfia para os legumes dalbergióides (clado das Papilionoideae pantropicais), sendo perdido, secundariamente várias vezes, em cada um dos clados Adesmia, Dalbergia e Pterocarpus.

Com relação às emergências externas, observadas em formação a partir dos ovários de botões florais, verificou-se que são as 
precursoras dos processos espiniformes do fruto. Bell (1991) relata a ocorrência de espinhos relacionados à dispersão de frutos, usualmente formados por emergências não vascularizadas, mas este não é o caso de $C$. tomentosum. Nesta espécie, os espinhos não atuam na dispersão, que é anemocórica.

Com o desenvolvimento do pericarpo de C. tomentosum, pode-se constatar a vascularização que caracteriza os espinhos propriamente ditos, segundo definem Vidal \& Vidal (2000). Como os feixes vasculares da espécie estudada são acompanhados por grande quantidade de fibras, os espinhos tornam-se rígidos e pontiagudos, certamente adaptando-se à função de proteção das sementes inclusas neste fruto.

Tradicionalmente, o fruto de $C$. tomentosum é classificado como sâmara (Vidal \& Vidal 2000; Spjut 1994; Barroso et al. 1999). Alguns autores como Dudik (1981), no entanto, propõem a utilização do termo legume para todos os frutos de leguminosas, independente de sua morfologia. Considerando a grande variabilidade carpológica das Papilionoideae, optou-se por manter o termo sâmara, que explicita claramente a estrutura observada na espécie em estudo.

Barroso et al. (1999) consideram a sâmara uma especialização do legume e afirmam que, nas leguminosas, podem ser encontrados frutos desse tipo com duas ou três sementes, separadas por tabiques transversais. Sâmaras assim estruturadas são observadas em C. tomentosum, embora os tabiques, sendo diferenciados a partir das emergências produzidas internamente no ovário, sejam oblíquos em sua maioria. Para outras espécies de Dalbergieae, relata-se a formação de tabiques transversais para Tipuana tipu (Benth.) Kuntze (Martins \& Oliveira 2001) e Pterocarpus violaceus Vogel (Nakamura \& Oliveira 2005). Estas subdivisões produzidas pelas emergências internas são também denominadas falsos septos, em função de serem formadas a partir de ovários não septados (Roth 1977).
As características anatômicas do pericarpo de $C$. tomentosum explicam sua indeiscência. Antes da fase de maturação (até o estádio III), prevalecem células de paredes delgadas e, quando espessadas, sem lignificação em todo o pericarpo. Na maturidade (estádio IV), contudo, a grande lignificação do estrato esclerenquimático mesocárpico e endocárpico e o arranjo irregular de suas células impedem a deiscência.

A estrutura desse pericarpo não se enquadra em nenhum dos tipos propostos por Fahn \& Zohary (1955). Apesar desses autores terem estudado cerca de 100 espécies de mais de 50 gêneros de leguminosas, não foram contempladas as sâmaras. Para Tipuana tipu, Martins \& Oliveira (2001) reconhecem o enquadramento no tipo Coronilla proposto por Fahn \& Zohary (1955), destacando, contudo, algumas pequenas variações do padrão.

Algumas características citadas por Dudik (1981) refletem o elevado grau de especialização dos frutos e sementes de Centrolobium tomentosum: fruto com poucas sementes, tendendo a monospérmico; fruto indeiscente e septado; semente campilótropa, exalbuminosa, sem alas ou arilos.

Estudos realizados com Tipuana tipu (Martins \& Oliveira 2001) e Pterocarpus violaceus (Nakamura \& Oliveira 2005), espécies também pertencentes à tribo Dalbergieae, mostram frutos com características estruturais gerais similares às de $C$. tomentosum, abrangendo a referida listagem de Dudik (1981). Como T. tipu e $P$. violaceus exibem uma única camada no estrato esclerenquimático, seu pericarpo pode ser considerado, segundo Fahn \& Zohary (1955), de estrutura intermediária entre os frutos mais primitivos (com duas camadas no estrato esclerenquimático) e os derivados (aqueles sem estrato esclerenquimático). A dupla camada esclerenquimática no pericarpo da espécie estudada sugere o plesiomorfismo de $C$. tomentosum em relação às duas espécies de Dalbergieae anteriormente citadas. 
O pericarpo de C. tomentosum apresentou o desenvolvimento característico dos frutos secos, partindo da estrutura ovariana (estádio I), passando pelo ciclo de crescimento por divisão celular (estádio II), seguido da fase de alongamento celular (estádio III) e lignificação do estrato esclerenquimático pericárpico (estádio IV). Este padrão também foi observado para Tipuana tipu (Martins \& Oliveira 2001), diferenciando-se do registrado para Pterocarpus violaceus, que apresentou seis estádios de desenvolvimento, visto que sua semente tem desenvolvimento posterior à lignificação do pericarpo (Nakamura \& Oliveira 2005).

Quanto ao desenvolvimento da semente, são relatados dois possíveis processos: Souza (1981) refere-se ao desenvolvimento da semente paralelamente ao do pericarpo, fato verificado neste trabalho para $C$. tomentosum e também por Martins \& Oliveira (2001) para Tipuana tipu; Oliveira \& Beltrati (1993) relatam a diferenciação seminal somente após a lignificação pericárpica, o que é observado também em $P$. violaceus (Nakamura \& Oliveira 2005). Segundo Roth (1977), nos frutos que desenvolvem prematuramente um tecido multisseriado que reveste a cavidade seminal ("seed cushion"), a pressão do pericarpo em desenvolvimento sobre a semente é amortecida, propiciando seu desenvolvimento paralelo. Do contrário, quando os tecidos esclerenquimáticos do mesocarpo e/ou endocarpo e o parênquima que reveste a cavidade seminal se formam em fase adiantada do amadurecimento (estádio IV), a semente só se diferencia após esta fase.

Em C. tomentosum foi observada a compressão e absorção do tegumento interno, no início da diferenciação seminal. Eames \& MacDaniels (1947) generalizaram que ocorre completa absorção do tegumento interno e do nucelo nas sementes de leguminosas. Embora a literatura registre numerosas exceções, este trabalho corrobora o estabelecido pelos autores supracitados.
A presença de inúmeros idioblastos fenólicos e sua fusão em canais no pericarpo, também observada no mesocarpo de Swartzia langsdorffii Raddi por Colpas \& Oliveira (2002), e o grande acúmulo de compostos fenólicos em toda a epiderme externa da testa são fatos que merecem destaque. Numerosos trabalhos relacionam a ocorrência dos compostos fenólicos à proteção do embrião, especialmente pela resistência que conferem contra patógenos (Suárez \& Engleman 1980). Quando o fruto é deiscente, os compostos fenólicos se concentram principalmente nos tegumentos, acumulando-se também em grandes quantidades nos pericarpos indeiscentes. Nos frutos de Dalbergieae, é abundante a ocorrência de compostos fenólicos, em especial calconas, isoflavonóides, neoflavonóides e quinonas que, contudo, têm sido pouco estudados (Polhill 1981).

As sementes de Leguminosae são, de modo geral, consideradas impermeáveis, sendo a escarificação um requisito para que a embebição e a germinação possam ocorrer (Corner 1951, Quinlivan 1971). No caso de C. tomentosum, observou-se que o pericarpo no núcleo seminífero apresenta cutícula, possui intensa lignificação e grande quantidade de compostos fenólicos, assumindo o papel do tegumento, que é delgado e pouco diferenciado, exibindo apenas alguns dos aspectos da estrutura típica das leguminosas relatada por Corner $(1951,1976)$. Tal fato era esperado, sendo a regra para sementes inclusas em pericarpos indeiscentes.

Embora a anatomia do tegumento revele estrutura muito simplificada se comparada ao tegumento típico das leguminosas, a morfologia do hilo avantajado, com barra de traqueídes na região sub-hilar, evidencia que $C$. tomentosum mantém as características mais marcantes das Papilionoideae (Corner 1951), que são constantes para as Dalbergieae já avaliadas. 


\section{Agradecimentos}

À FAPESP, pela bolsa de iniciação científica concedida a A. C. N. Siqueira (Processo no 99/02393-0).

\section{REFERÊnCIAS BIBLIOGRÁFICAS}

Barroso, G. M.; Morim, M. P.; Peixoto, A. L. \& Ichaso, C. L. F. 1999. Frutos e sementes: morfologia aplicada à sistemática de dicotiledôneas. Editora UFV, Viçosa, 443p.

Barroso, G. M.; Peixoto, A. L.; Ichaso, C. L. F.; Costa, C. G.; Guimarães, E. F. \& Lima, H. C. 1984. Vol. 2. Sistemática de Angiospermas do Brasil. Imprensa Universitária da Universidade Federal de Viçosa, Viçosa, 377p.

Bell, A. D. 1991. Plant form: an illustrated guide to flowering plant morphology. University Press, Oxford, 341p.

Bukatsch, F. 1972. Bemerkungen zur Doppelfärbung Astrablau-Safranin. Mikrokosmos 61(8): 255.

Burger, L. M. \& Richter, H. G. 1991. Anatomia da Madeira. Nobel, São Paulo, 160p.

Colpas, F. T. \& Oliveira, D. M. T. 2002. Structure and ontogeny of Swartzia langsdorffii (Leguminosae) pericarp. Nordic Journal of Botany 22(3): 313-323.

Corner, E. J. H. 1951. The leguminous seed. Phytomorphology 1:117-150.

1976. The seeds of dicotyledons. Vol. 1. University Press, Cambridge, 311p.

Diaz, P. 1992. Araribá (Centrolobium tomentosum Guillem. ex Benth. Fabaceae): revisão bibliográfica de essência nativa de grande potencial silvicultural. Revista do Instituto Florestal 4(2): 430-434.

Dudik, N. M. 1981. Morphology of the pods of Leguminales (Fabales). In: Polhill, R. M. \& Raven, P. H. (eds.). Advances in legume systematics. Part 2. Royal Botanical Gardens, Kew. Pp.897-901.

Eames, A. J. \& MacDaniels, L. H. 1947. An introduction to plant anatomy. 2 nd.ed. Tata McGraw-Hill Publishing, New Delhi, 427p.
Fahn, A. 1979. Secretory tissues in plants. Academic Press, London, 302p.

\& Zohary, M. 1955. On the pericarpial structure of the legumen, its evolution and relation to dehiscence. Phytomorphology 5(1): 99-111.

Jensen, W. A. 1962. Botanical histochemistry: principles and pratice. W. H. Freeman, San Francisco, 408p.

Johansen, D. A. 1940. Plant microtechnique. McGraw-Hill Book, New York, 523p.

Lavin, M.; Pennington, R. T.; Klitgaard, B. B.; Sprent, J. I.; Lima, H. C. \& Gasson, P. E. 2001. The dalbergioid legumes (Fabaceae): delimitation of a pantropical monophyletic clade. American Journal of Botany 88(3): 503-533.

Lilleland, O. 1930. Growth study of the apricot fruit. Proceeding of the American Society for Horticultural Science 27: 237-245.

Lilleland, O. 1932. Growth study of the peach fruit. Proceeding of the American Society for Horticultural Science 29: 8-12.

Lilleland, O. 1933. Growth study of the plum fruit - I. The growth and changes in chemical composition of the climax plum. Proceeding of the American Society for Horticultural Science 30: 203-208.

Lima, H. C. 1989-1990. Tribo Dalbergieae (Leguminosae Papilionoideae) - morfologia dos frutos, sementes e plântulas e sua aplicação na sistemática. Arquivos do Jardim Botânico do Rio de Janeiro 30: 1-42.

Lorenzi, H. 1992. Árvores brasileiras: manual de identificação e cultivo de plantas arbóreas nativas do Brasil. Vol. 1. Plantarum, Nova Odessa. Pp.196.

Martins, M. A. G. \& Oliveira, D. M. T. 2001. Morfo-anatomia e ontogênese do fruto e semente de Tipuana tipu (Benth.) O. Kuntze (Fabaceae: Faboideae). Revista Brasileira de Botânica 24(1): 109-121.

Nakamura, A. T. \& Oliveira, D. M. T. 2005. Morfoanatomia e ontogênese da sâmara de Pterocarpus violaceus Vogel (Fabaceae: Faboideae). Revista Brasileira de Botânica 28(2): 375-387. 
Nitsch, J. P. 1953. The physiology of fruit growth. Annual Review of Plant Physiology 4: 199-236.

O'Brien, T. P.; Feder, N. \& McCully, M. E. 1964. Polychromatic staining of plant cell walls by toluidine blue O. Protoplasma 59: 368-373.

Oliveira, D. M. T. 1999. Morfo-anatomia do embrião de leguminosas arbóreas nativas. Revista Brasileira de Botânica 22(3): 413-427.

\& Beltrati, C. M. 1993. Aspectos anatômicos dos frutos e sementes de Inga fagifolia Willd. (Fabaceae: Mimosoideae). Revista Brasileira de Biologia 53(4): 625-636.

\& Paiva, E. A. S. 2005. Anatomy and ontogeny of Pterodon emarginatus (Fabaceae: Faboideae) seed. Brazilian Journal of Biology 65(3): 483-494.

Pennington, R.; Lavin, M.; Hireland, H.; Klitgaard, B.; Preston, J. \& Hu, J. 2001. Phylogenetic relationships of basal papilionoid legumes based upon sequences of the chloroplast $t r n L$ intron. Systematic Botany 26(3): 537-556.

Pietrobom, R. C. V. \& Oliveira, D. M. T. 2004. Morfoanatomia e ontogênese do pericarpo de Schizolobium parahyba (Vell.) Blake (Fabaceae, Caesalpinioideae). Revista Brasileira de Botânica 27(4): 767-779.

Pijl, L. van der. 1982. Principles of dispersal in higher plants. 3rd.ed. Springer-Verlag, Berlin, 215p.

Polhill, R. M. 1981. Dalbergieae. In: Polhill, R. M. \& Raven, P. H. (eds.). Advances in legume systematics. Part 1. Royal Botanical Gardens, Kew. Pp. 233-242.

; Raven, P. H. \& Stirton, C. H. 1981.

Evolution and systematics of the Leguminosae. In: Polhill, R. M. \& Raven, P. H. (eds.). Advances in legume systematics. Part 1. Royal Botanical Gardens, Kew. Pp.1-26.

Prenner, G. 2004. New aspects in floral development of Papilionoideae: initiated but suppressed bracteoles and variable initiation of sepals. Annals of Botany 93: 537-545.

Quinlivan, B. J. 1971. Seed coat impermeability in legumes. The Journal of the Australian Institute of Agricultural Science 37:283-293.

Radford, A. E.; Dickison, W. C.; Massey, J. R. \& Bell, C. R. 1974. Vascular plant systematics. Harper \& Row, New York, 891p.

Roth, I. 1977. Fruits of angiosperms. Gebrüder Borntraeger, Berlin, 675p. (Handbuch der Pflanzenanatomie).

Sass, J. E. 1951. Botanical microtechnique. 2nd.ed. State Press, Iowa, 228p.

Souza, L. A. 1981. Desenvolvimento anatômico e comparativo dos frutos de Acacia paniculata Willd. (Leg. - Mimosoideae) e Lonchocarpus muehlbergianus Has. (Leg. - Faboideae). Tese de Doutorado. Universidade de São Paulo, São Paulo, 261p.

Spjut, R. W. 1994. A systematic treatment of fruit types. Memoirs of the New York Botanical Garden 70:1-182.

Suárez, G. R. \& Engleman, E. M. 1980. Deposito de taninos en la testa de Amaranthus hypochondriacus L. (alegria). Agrociencia 42:35-50.

Theobald, W. L.; Krahulik, J. L. \& Rollins, R. C. 1979. Trichome description and classification. In: Metcalfe, C. R. \& Chalk, L. (eds.). Anatomy of the dicotyledons. 2nd.ed. Vol.1. Claredon Press, Oxford. Pp. 40-53.

Thomas, V. 1991. Structural, functional and phylogenetic aspects of the colleter. Annals of Botany 68: 287-305.

Tukey, H. B. \& Young, J. O. 1939. Histological study of the developing fruit of the sour cherry. Botanical Gazette 100: 723-749.

Vidal, W. N. \& Vidal, M. R. R. 2000. Botânica - Organografia: quadros sinóticos ilustrados de fanerógamos. 4a ed. Imprensa Universitária, Viçosa, 124p. 